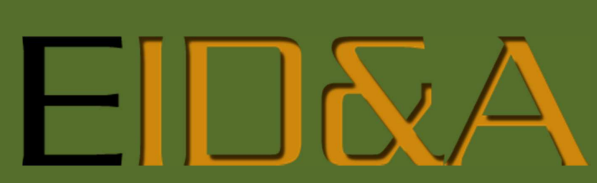

Revista Eletrônica de Estudos Integrados em Discurso e Argumentação

dx.doi.org/10.17648/eidea-16-2228

\title{
IMAGENS DA POLÍTICA, POLÍTICA DAS IMAGENS: SOBRE COMUNICAÇÃO, RETÓRICA E ESTÉTICA
}

\section{Mariano Dagatti ${ }^{\mathrm{i}}$}

Resumo: Este artigo explora uma dimensão fundamental da política e sua interpenetração com os regimes midiáticos: o da estética política, entendida como gramática do espetáculo do poder. Analisam-se os casos das duas forças políticas argentinas mais importantes do século XXI: Kirchnerismo e Cambiemos, a partir de um corpus de imagens disseminadas em sistemas de mídia de massa e baseadas na Internet. Trata-se de descrever a retórica dominante de seus discursos visuais, os modos de organizar sua encenação, os modos de imaginar a política (eminentemente, a relação da esfera política com a cidadania). Entendemos que o estudo da estética política nos permite lançar luz sobre os aspectos inexplorados da hegemonia discursiva.

Palavras-chave: Estética política. Retórica. Espetáculo. Hegemonia discursiva

\begin{abstract}
This article explores a fundamental dimension of politics and its interpenetration with media regimes: that of political aesthetics, understood as grammars of the spectacle of power. The cases of the two most important Argentine political forces of the 21st century are analyzed: Kirchnerismo and Cambiemos, based on a corpus of images disseminated in mass media systems and based on the Internet. It is about describing the dominant rhetorics of their visual discourses, the ways of organizing their staging, the ways of imagining politics (eminently, the relationship of the political sphere with citizenship). We understand that the study of political aesthetics allows us to shed light on unexplored aspects of discursive hegemony.
\end{abstract}

Keywords: Political aesthetics. Rhetoric. Espetaculo. Discursive hegemony.

\footnotetext{
' Docente da Universidade de Buenos Aires (UBA) e pesquisador do Conselho Nacional de Investigações Científicas e Técnicas (CONICET), Argentina. E-mail: mjdagat@yahoo.com.ar
} 
EID\&A - Revista Eletrônica de Estudos Integrados em Discurso e Argumentação, Ilhéus, n. 16 esp. "Discurso e argumentação na política latino-americana, set.2018.

\section{Introdução}

A política está repleta de imagens. Imagens de manifestações populares, com líderes inflamados e públicos acalorados, imagens de gestos grandiloquentes à espera de câmeras ou de pequenos signos captados na fugacidade do instante, imagens de reuniões sigilosas, cheias de poses e formas, imagens de manifestações de ruas, imagens de cartazes variados que enchem a via pública com rostos sérios, sorridentes, inspirados, promissores, convencidos; imagens de debates irrisórios, de entrevistas permissivas, imagens de publicidades audiovisuais, com suas frases ilusórias, seus jingles pegajosos. A política não se limita às imagens, porém não há política sem imagens. Os principais meios de comunicação contemporâneos, de maneira considerável, a televisão em primeiro e a Internet com sua atualidade, talvez tenham exacerbado esta faceta até o ponto de confundi-la com sua própria substância, fazendo da política um espetáculo, isto é, um objeto de contemplação, de observação, de olhada e, por um desvio nada casual, um objeto de sedução, de comoção, que se subtrai ao logos, naquilo que o inefável parece convergir com o irracional.

Os perigos da imagem são um tema que acompanha o desenvolvimento das principais ciências do sentido, seja pelas dificuldades que seu acesso implica ou pelas armadilhas que oferece a seus espectadores. O artigo clássico de Roland Barthes, Retórica da imagem, que data de 1964, ainda que apenas iniciada sua aventura semiológica, dava conta de que a imagem era, muitas vezes, vista como "um lugar de resistência ao sentido" e, portanto, a significação não poderia, de modo algum, esgotar sua inefável riqueza. De que modo a imagem adquire sentido? Onde termina o sentido? E se termina, o que há depois dele? A imagem apresentava ao analista como uma caixa preta, repleta de segredos, indeterminações e truques analógicos, em cuja semelhança com o real, sua capacidade de imitação do real, ameaçava nos prender com maior facilidade na armadilha da referência.

Do ponto de vista do espectador, a questão resultava ainda mais problemática. A imagem, ao se poupar da palavra, apostava menos em convencer o espectador do que em comovê-lo com a força analógica e geralmente indicial de sua representação plástica. O peso da imagem na política ganhou progressiva força a partir da presença da televisão como meio massivo por excelência, entre as décadas de 1960 e 1990, dependendo dos avatares históricos de cada região e país. (Se o debate Nixon-Kennedy foi um 
EID\&A - Revista Eletrônica de Estudos Integrados em Discurso e Argumentação, Ilhéus, n. 16 esp. "Discurso e argumentação na política latino-americana, set.2018.

marco nas campanhas políticas nos Estados Unidos, como pode ser visto na temporada inicial de Mad Man, na Argentina, foram os anos noventa os que vieram a se consagrar ao espetáculo televisivo como dimensão fundamental do aspecto público da política). Esse peso progressivo da política-espetáculo, que se apresentava aos olhos dos principais interessados como irresistível e inevitável, fez da problemática da imagem um assunto de interesse público, que atraiu por igual a atenção dos diversos atores políticos, comunicacionais e socioculturais.

A mediatização da política tem sido associada com frequência ao crescente domínio da chamada "política-espetáculo". A televisão surge nessa representação como rainha da midiatização da face pública da política. Não há dúvida de que nos últimos 30 anos esta instituição/representação tem sua força de verdade e não admite muitos matizes. No entanto, é possível sustentar uma tese distinta se levada em consideração a história da midiatização da política por uma perspectiva mais ampla: foram justamente a imprensa primeiro e a radio depois que fizeram do aspecto público da política um assunto de palavra antes que de imagem. O predomínio do logos em detrimento da encenação da política (e de seus principais vetores: a imagem, o corpo, o espetáculo) esteve paradoxalmente associado às primeiras grandes fases da conformação do sistema de meios massivos: a era da imprensa industrial (desde finais do século XIX), a era do rádio (a partir dos anos 20 do século passado). Eras da palavra, nas quais as imagens da política eram secundárias ou marginais em relação aos meios dominantes cotidianos (a consolidação do cinema supõe matizes sobre o núcleo duro desses argumentos, mas tendo a crer que não afetam sua verdade).

O espetáculo tem sido parte constituinte da política desde as próprias origens do tratamento dos assuntos públicos. A actio, uma das cinco fases principais da Retórica Antiga, remete diretamente ao ato de pronunciar um discurso efetivo: a gestualidade, a variação da voz, o contato visual com a audiência, a entonação e a dicção oportuna são todas necessárias para uma encenação bem sucedida. Somente com a televisão, a actio, a dimensão corporal da oratória política, voltará aos primeiros planos do tratamento público do político. Quero dizer a mediatização da política, ao contrário do que sugere certos lugares comuns, não fez da política um espetáculo, se não um assunto de palavra. Somente com a televisão, midiatização da política e espetáculo se encontram para traçar um convênio que parece inabalável até 
EID\&A - Revista Eletrônica de Estudos Integrados em Discurso e Argumentação, Ilhéus, n. 16 esp. "Discurso e argumentação na política latino-americana, set.2018.

os dias de hoje, ainda que não faltem estratégias políticas que se orientem em um sentido contrário.

Em 1957, Roland Barthes publica, em Mitologias, um conjunto de textos decisivos para uma crítica ideológica dirigida à linguagem da chamada cultura de massas e sua desmontagem semiológica. Esse projeto, que se distanciava da simples denúncia para se orientar a uma detalhada exploração das representações coletivas, tomava como ponto de partida alguns "mitos" da sociedade francesa daqueles tempos: a gastronomia popular ou gourmet, a informação jornalística, a poesia infantil, o cinema industrial, o contraste (certamente atual) entre os usuários e as greves, as publicidades comerciais, o turismo e seu afã pela autenticidade, pelas exposições, pelos brinquedos, pela luta livre (o catch).

O movimento da crítica de Barthes se apresentava a contrassenso do sentido comum; seu objetivo consistia em manifestar o que ele chamava de "o abuso ideológico da evidência" pequeno-burguesa: o que o mito cristalizava como eterno e natural era, ao contrário, o produto surdo de processos históricos a ser descoberto, desarmado, desativado. Recordemos, como exercício, os desenhos animados de nossa infância: há milhares de anos, na pré-história de Os Flintstones, os seres humanos formavam famílias heterossexuais, tinham filhos (uma mulher e um homem) e um animal de estimação muito parecido com nossos cães e gatos, utilizavam um tipo de proto-automóvel para se locomover nas cidades e iam aos shopping centers para saciar o vício do consumo. E, aparentemente, não será muito diferente no futuro: Os Jetsons, outro produto, como Os Flintstones, do estúdio de animação Hanna-Barbera, nos mostram também um futuro cujos costumes resultam demasiadamente parecidos aos dos "Trinta Gloriosos" que vão do fim da Segunda Guerra Mundial até a crise do petróleo em 1973. Famílias modelo, mascote, automóvel, shopping center, empregados domésticos (robôs, por sorte!), chefes carrancudos e companheiros de trabalho menos solidários que competitivos.

Volto a Roland Barthes. O pequeno ensaio intitulado "Fotogenia eleitoral" forma parte da proposta desmistificadora de Mitologias. A partir de folhetos, Barthes analisa, com base no modelo da arte e da retórica de Aristóteles, uma característica que para a época constituía uma novidade: a 
EID\&A - Revista Eletrônica de Estudos Integrados em Discurso e Argumentação, Ilhéus, n. 16 esp. "Discurso e argumentação na política latino-americana, set.2018.

inclusão de fotografias, como retratos, dos candidatos ${ }^{1}$. De acordo com Barthes, o poder dessas imagens residia na capacidade de conversão, na possibilidade de estabelecer um nexo pessoal, emocional, com os eleitores, mas além dos programas políticos enunciados verbalmente. Segundo Barthes, na medida em que a fotografia é elipse da linguagem, privilegia-se a encenação de uma "maneira de ser", uma situação sócio-moral que faz inibir a esfera racional da política (entendida como uma série de problemas e soluções): ${ }^{2}$

O uso da fotografia eleitoral supõe, naturalmente, uma cumplicidade: a foto é espelho, oferece em leitura não familiar, o conhecido, propõe ao leitor sua própria efígie, clarificada, magnificada, orgulhosamente transladada ao estado de tipo. Esta ampliação, por outro lado, define exatamente a fotogenia: o eleitor se encontra expressado e transformado em herói, é convidado a eleger-se a si mesmo, a carregar o mandato que se concluirá com uma verdadeira transferência física: delega sua “casta” (BARTHES, 2004, p.166).

A citação é reveladora no seguinte sentido. Dá conta de uma espécie de movimento pendular, próprio do pensamento francês do século $X X^{3}$, entre o interesse e a desconfiança em relação à fotografia. No final dos anos cinquenta, enquanto a França acomodava-se a uma nova era do capitalismo industrial, Barthes observava com suspeita os poderes de sedução, perturbação e encantamento das imagens. Nos últimos cinquenta anos, a suspeita não fez mais que aumentar tão exponencialmente como as imagens. Jonh Berger afirma que:

em nenhum outro tipo de sociedade da história tem havido tanta concentração de imagens, tal densidade de mensagens visuais. Pode-se recordar ou esquecer estas mensagens, mas as capta por breves momentos, e durante um instante estimulam a imaginação, seja por meio da lembrança ou da expectativa. (BERGER, 2000, p.143)

\footnotetext{
${ }^{1}$ A teoria da fotogenia havia sido elaborada por Edgar Morin (2011) em El cine o el hombre imaginario. Em termos de estrutura informativa, "na fotogenia, a mensagem conotada está na mesma imagem 'embelezada' (quer dizer, sublimada, em geral) pelas técnicas de iluminação, impressão e reprodução” (BARTHES, 2014, p.21).

2 "Podemos assumir que o que sucedeu desde uma publicação de Mitologias é que a desmistificação não acabou com o mito, senão que, paradoxalmente, Ihe deu maior liberdade. Era uma vez... políticos que podiam passar vergonha se fossem acusados de trabalhar para promover sua imagem pública, mas com o passar do tempo, na medida em que a desmistificação se tornou mais frequente, a vergonha diminuiu, e agora um candidato discute publicamente como está tentando mudar sua imagem", observa Jonathan Culler (2002).

3 Trata-se de uma ambivalência em relação ao ocularcentrismo moderno que atravessa 0 pensamento francês do século XX - tal como foi estudado por Martin Jay (2007). A desconfiança do pensamento francês diante da imagem não é nenhuma novidade, como já foi magnificamente exposto em Ojos abatidos. La denigración de la visión en el pensamiento francés del siglo XX. O título é suficientemente enfático para exigir maiores esclarecimentos.
} 
EID\&A - Revista Eletrônica de Estudos Integrados em Discurso e Argumentação, Ilhéus, n. 16 esp. "Discurso e argumentação na política latino-americana, set.2018.

Tratemos de sintetizar os argumentos precedentes com a finalidade de tomar um novo impulso. Ocorrem então, simultaneamente, dois processos. Primeiro processo: a terceira fase de conformação do sistema de meios massivos, a da televisão (somando-se a da prensa e a do rádio), exalta o lado espetacular do aspecto público da política (lado que, como dissemos anteriormente, é parte constituinte da política e que se tornou esquecido ou ignorado durante as primeiras ondas da midiatização). Segundo processo: 0 espetáculo político é considerado uma versão desvalorizada da verdadeira política, a do logos, a dos argumentos, a dos programas, a das ideologias (com letra maiúscula), a dos projetos explícitos, com seus preceitos e enumerações.

O espetáculo é vislumbrado como o fim da política, no duplo sentido da palavra: para o campo político, porque se trata de lograr o melhor espetáculo possível; para o campo intelectual, porque o espetáculo conduz ao fim da política, se entendermos a política como a tarefa de organizar formas de viver juntos. Sob tal perspectiva, o espetáculo tornaria a política heterônoma.

Tomemos um caso emblemático. Homo Videns, de Giovanni Sartori. O que diz Sartori (1998) em seu exaustivamente difundido texto? Se tomarmos a questão desde um olhar antropológico, de modo transversal aos diferentes campos da práxis humana, Sartori afirma que o vídeo, entendido como a superfície da tela, está transformando o homo sapiens, produto da cultura escrita, em um homo videns para o qual a palavra se encontra destronada pela imagem. Por essa razão, a televisão é para Sartori um instrumento antropogênico: gera um novo tipo de ser humano. A preponderância do visível sobre o inteligível nos levará a ver sem entender: perderíamos a capacidade de gerar conceitos a partir das percepções.

A televisão, de acordo com Santori (1998), inverte a evolução do sensível em inteligível e o converte em um regresso ao puro e simples ato de se ver. A televisão produz imagens e anula conceitos e, desse modo, atrofia nossa capacidade de abstração; logo, de entendimento.

O que é a videopolítica? Ela remete à incidência do vídeo nos processos políticos. Sartori distingue duas áreas de incidência: a formação de uma opinião pública heterodirigida, por um lado; e, por outro, a configuração do processo político, tanto no que refere ao ciclo eleitoral quanto ao modo habitual do governo. Com respeito à primeira delas, Sartori considera, em tipo de denúncia teórica, que a televisão se exibe como porta-voz de uma opinião pública que, na realidade, é seu próprio eco. Os mecanismos são conhecidos: 
EID\&A - Revista Eletrônica de Estudos Integrados em Discurso e Argumentação, Ilhéus, n. 16 esp. "Discurso e argumentação na política latino-americana, set.2018.

sondagem de opiniões, entrevistas e estatísticas ad hoc (o qualitativo e o quantitativo convergem como provas extra-técnicas a favor do argumento do dispositivo).

Com respeito à segunda delas, a configuração do processo político, Sartori conclui que a videopolítica conduz a uma mutação da política, que só pode ser vista como decadente. As nominalizações são abundantes em sua descrição: personalização, emotivização, aldeanização, vulgarização. Talvez nenhuma seja tão problemática para o tempo presente quanto esse tipo de paradoxo que é a construção de um cidadão hiperinformado e, não obstante, ignorante: porque a informação não se traduz necessariamente em conhecimento.

Todavia, Sartori era uma voz clamando no deserto. A preocupação pelo poder dos meios de comunicação, e sobretudo da televisão, para ditar suas normas, suas regras e seus valores aos agentes do campo político envolvia diferentes disciplinas, desde a semiótica até a sociologia e a antropologia políticas. A progressiva heteronomia do campo político é, de fato, uma problemática que remete aos trabalhos do sociólogo Christian Le Bart (1998), herdeiro da tradição de P. Bourdieu e L. Boltanski.

Le Bart (1998) formula essa problemática nos seguintes termos: o campo político, diferentemente de outros campos como a filosofia, o direito, a literatura, que podem desfrutar dessa autônoma ficção, não está encerrado em si mesmo, não pode autonomizar completamente, porque há uma tensão constitutiva do político entre autonomia e heteronomia, já que suas regras, suas operações, suas estratégias estão atravessadas inevitavelmente por regras, operações e estratégias de outras instituições e outros atores (os meios de comunicação, os cidadãos). Essa tensão faz com que valores marginais ou heterogêneos do campo político adquiram pouco a pouco um peso inusitado. A personalização é, para Le Bart, a mais notável delas, já que parece ir à contramão da mesma base do político que é a construção do comum, de identidades, de espaços e públicos de longa ou média duração.

Partindo da antropologia política, G. Balandier (1994) se perguntaria, em seu livro $O$ poder em cenas, pela relação entre a cultura midiática e o exercício da política, e afirmaria que a midiatização generalizada do âmbito político provocaria (e retroalimentaria) os processos de crises de representação e exasperação do espetáculo que definiram os traços do campo político no último quarto do século XX. (Traços que, por outro lado, se perpetuam ainda 
EID\&A - Revista Eletrônica de Estudos Integrados em Discurso e Argumentação, Ilhéus, n. 16 esp. "Discurso e argumentação na política latino-americana, set.2018.

hoje sob diferentes mecanismos e modalidades). Desse modo, explica Balandier (1994), os sistemas de ideia são deixados de um lado em função do predomínio da reputação, noção maquiavélica por excelência, que alguns autores, como H. Adverse (2009) no Brasil, conectam diretamente (e com argumentos dignos) com a prova retórica do ethos.

Não obstante, essa enésima denúncia do espetáculo político encontra, nas páginas de Balandier (1994), matizes que devem ser levadas em consideração. Quanto à sua preocupação pelo advento da política atrelada ao ecossistema midiático, Balandier aponta um fato relevante: o político não foi historicamente uma arte dos rituais, uma "teatrocracia" segundo sua definição, que envolve doses equivalentes de drama e tragédia. Sabemos que - drama e a tragédia implicam, com diferentes regras genéricas, a representação (imitação ou mimesis) de algum episódio ou conflito da vida dos seres humanos ou divinos, que inspira compaixão ou temor e gera no espectador, através das emoções, a purificação (catarsis). A analogia entre teatro e política implica, em Balandier, uma consideração do caráter espetacular, cênico, da política. Ruth Amossy (2014) parece conduzir seus argumentos na mesma direção quando, em seu recente livro Apologia da polêmica, destaca que a polêmica cumpre certas funções balanceadoras dentro dos regimes democráticos, por favorecer uma gestão democrática do conflito. Uma dessas funções está diretamente ligada à condição espetacular da polêmica: a encenação do conflito oferece, aos olhos dos cidadãos, a certeza das tensões que alimentam a vida política democrática, ao mesmo tempo em que garante a estabilidade do sistema, a partir da regulação de suas tensões e suas propostas.

Em continuidade com os argumentos anteriores, gostaria agora de fazer referência a um artigo de Beatriz Sarlo (1996), denominado "Siete hipótesis sobre la videopolítica", que foi publicado em seu livro Instantáneas ,de 1996. Nesse texto, Sarlo retoma o mencionado ensaio de Sartori e propõe uma visão nuançada dos efeitos da videopolítica na conformação da esfera pública do final do século XX.

Por questões de espaço, irei me referir às sete hipóteses de um modo sucinto, e não pretendo outra coisa além de sublinhar certos tópicos que venham a adquirir uma dimensão real na parte final do meu artigo. Primeira hipótese: a videopolítica é a forma mais visível do aspecto público da política. Implica uma estética, isto é, refere a toda a região da percepção conceptual. A 
EID\&A - Revista Eletrônica de Estudos Integrados em Discurso e Argumentação, Ilhéus, n. 16 esp. "Discurso e argumentação na política latino-americana, set.2018.

segunda hipótese assinala que a videopolítica oferece formas aparentemente não mediadas de apresentação das questões públicas. Ou seja, um fenômeno midiático se apresenta como se não houvesse mediação. $O$ dever da visibilidade pública se conjuga com os ideais do imediatismo e transparência, que ocasionam efeitos de proximidade e familiaridade. Estes, como nos lembra N. Luhmann (2005), são operadores de confiança fundamentais na configuração dos sistemas sociais.

A videopolítica dessacraliza a política. Esta é a terceira hipótese em questão. Resulta, nesse sentido, para Sarlo (1996), uma etapa a mais, tipicamente moderna, da mudança de escala entre cidadãos e políticos. Em uma análise cuidadosa sobre os programas políticos de opinião, três semiólogos argentinos, C. Centocchi, S. Tatavitto e G. Varela (2003), mencionam, por exemplo, como as dinâmicas de midiatização implicam em termos de esfera pública uma ampliação do dizer político, marcado pela convivência do discurso político com gêneros alheios a seu campo. o que você come?, quem faz as compras em casa?, como conheceu sua esposa?, você é romântico?, leva seus filhos à escola?, qual é seu corte de carne favorito?, massas ou churrasco?, cinema industrial ou independente?, assiste novelas?, o que te faz feliz? Se se tratasse de um espaço íntimo, faria mais sentido, mas ao ligar a televisão, a qualquer momento do dia, pode-se estar inteirado de que o presidente gosta de passear pela manhã e tomar um sorvete contemplando o pôr do sol. A figura do político aparece desdobrada por consequência: é um homem comum e um ser excepcional ao mesmo tempo.

Quarta hipótese: a videopolítica adota uma forma discursiva mais sensível e acessível que a das instituições deliberativas do sistema político. Quinta hipótese: a videopolítica vive em um puro presente: o tempo midiático, o tempo da atualidade, causa erosão, carcome o tempo político, o das tradições, o dos paulatinos movimentos tectônicos do campo. A política se torna um assunto cotidiano, marcado oportunamente por acontecimentos extraordinários, que não fazem mais que valorar (em boa medida comercialmente) o efêmero acima do tempo maior das identidades. Assim, e esta é a sexta hipótese, a videopolítica define um novo tipo de acontecimento público especialmente criado para integrar-se em seu continuum.

A sétima hipótese de Sarlo sugere que a videopolítica transforma a democracia representativa em democracia de opinião. O efeito desta operação é uma extensão cultural da política na vida: a política permeia os 
EID\&A - Revista Eletrônica de Estudos Integrados em Discurso e Argumentação, Ilhéus, n. 16 esp. "Discurso e argumentação na política latino-americana, set.2018.

diferentes estratos da esfera privada e pública (comemos assistindo o discurso do presidente, presenciamos uma reunião em rede nacional), enquanto, de forma simultânea, se "democratizam" os lugares de enunciação: o vizinho opina sobre as obras de iluminação pública em sua rua, o taxista enuncia seu programa para uma educação do futuro, o professor comenta qual é o melhor sistema para organizar o sistema de transporte etc.

I

Qualquer que seja nossa leitura da política contemporânea, fica claro que o peso dado ao espetáculo político não apenas tomou como princípio indiscutível que a videopolítica incide na política (e não o contrário), mas também deixou de lado por conveniência toda a atenção sobre a questão dos cidadãos, sobre as lógicas dos atores sócio-individuais, para se deter apenas nas propostas entre as elites políticas e as corporações midiáticas. Se isso era um problema grave ao se pensar na terceira fase da midiatização - a da televisão -, fica diretamente insustentável ao se pensar na quarta fase, aquela que M. Carlón (2015)denominou "as sociedades hipermidiatizadas", a etapa da Internet, ou seja, o que E. Verón (2013) chamou de "a revolução do acesso".

Os acelerados processos de midiatização das sociedades denominadas "pós-industriais", desde a diversificação da oferta de televisão até a influência da Internet e das redes sociais digitais, têm incrementado a complexidade dos circuitos de circulação semiótica; entre eles, os do campo político. O desenvolvimento da Internet e do sistema de mídia baseado na Internet torna ainda mais complexo o ecossistema midiatizado herdado do reino da televisão. Os processos de interação com os meios massivos de comunicação e com os meios baseados na Internet têm gerado não apenas novos tipos de discursos políticos e novos modos de fazer campanha, por exemplo, mas também novos modos de consumir a política, de participar na política e de avaliar ou controlar as operações do campo político (VERÓN, 2007; CARLÓN, SCOLARI, 2009).

Em outras palavras, a hipermidiatização da sociedade implica uma aceleração e uma retroalimentação do que Rosanvallon (2007) chama de "a contrademocracia"; isto é, o conjunto de modalidades que visam expressar e organizar a confiança democrática, a crescente lacuna entre representantes e representados. Conforme Rosanvallon, não se deve entender esta forma política, de nenhuma maneira, como o contrário da democracia, mas como uma forma de democracia que se contrapõe à outra. Entendamo-nos: é a 
EID\&A - Revista Eletrônica de Estudos Integrados em Discurso e Argumentação, Ilhéus, n. 16 esp. "Discurso e argumentação na política latino-americana, set.2018.

democracia dos poderes indiretos disseminados no corpo social, a democracia da desconfiança organizada diante da democracia da legitimidade eleitoral. Desse modo, esta contrademocracia conforma um sistema com as instituições democráticas legais. Tem como objetivo prolongar e estender seus efeitos. São mecanismos contrademocráticos: a vigilância, a denúncia, a oposição política, a judicialização da política etc.

De todo modo, a menção de "contrademocracia" não é casual. A lógica da política em sociedades hipermidiáticas deve ser considerada como um dos fenômenos menos trabalhados e mais inovadores da atual situação: o dos novos estilos de cidadanias políticas. De fato, a mutação do ecossistema midiático e as mudanças nas formas de relação entre mídias e política coexistem com novas formas de conceber, praticar e consumir a política por parte dos cidadãos.

Gostaria de levantar aqui os argumentos de Dalton (2014), em Citizen politcs, uma obra que considero relevante para compreender as relações entre política, mídias e cidadania no século XXI. Os novos estilos de cidadania estão associados, segundo Dalton, a quatro fenômenos convergentes: 1) os processos de mobilização cognitiva; 2) as mudanças nos modos de participação política; 3) a desestruturação das clivagens tradicionais de diferenciação social; 4) o crescimento dos determinantes imediatos e de médio prazo na conduta dos indivíduos (agenda setting, reputação dos candidatos, acontecimentos político-midiáticos como escândalos ou manifestações multitudinárias).

Tratemos de sintetizar os principais tópicos de cada fenômeno conforme a descrição de Dalton (2014). Em primeiro lugar, os novos estilos de cidadania política estão associados a processos de mobilização cognitiva. A pergunta que orienta este processo é a seguinte: que grau de satisfação política é necessário para viver em uma sociedade democrática? Para que a democracia funcione, assumimos que os cidadãos devem ter um nível básico de habilidades ou conhecimentos políticos. Estas habilidades ou conhecimentos, muitas vezes, são moldados em diálogo com os grupos sociais de pertencimento, os partidos políticos, os sistemas de mídia massiva e com base na Internet etc. Na atualidade, e em parte como resultado do novo ecossistema midiático, temos mais capacidade de obter informação (por exemplo, acessamos a mais fontes de informação ou fazemos leituras que 
EID\&A - Revista Eletrônica de Estudos Integrados em Discurso e Argumentação, Ilhéus, n. 16 esp. "Discurso e argumentação na política latino-americana, set.2018.

excedem os contratos de leitura de cada mídia) e mais capacidade para processar informação (o que não significa estar melhor informados).

Em segundo lugar, os novos estilos de cidadania estão associados a mudanças nos modos de participação política. Contra o mito do cidadão passivo, Dalton (2014) insiste na ideia de que estamos presenciando um crescimento das competências e dos recursos políticos da cidadania. Acontece que os cidadãos têm outros tipos de participação, além do voto, as campanhas e os partidos, que não podem ser avaliados com as regras destes modos clássicos: agora o contato direto, as atividades em grupo, os protestos, as ações de conflito (escrache), o ativismo na web têm um peso diferente na própria concepção que cada ator faz de sua participação. Certamente, nem todos têm o mesmo grau de eficácia, o que depende do grau de conflito, do esforço exigido e da cooperação com outras pessoas. Assim, é previsível que uma mobilização em massa tenha uma maior eficácia de pressão do que um retweet perdido de um internauta. Contudo, um número elevado (exponencial) de retweets, devido a seu caráter imediatamente público, pode instalar na agenda de mídia de massa temas que de outra forma seriam invisíveis ou "escondidos".

Os novos estilos de cidadania política estão associados, em terceiro lugar, com a ruptura das tradicionais divisões políticas e sociais e com a estruturação de divisões axiológicas e temáticas momentâneas. Se antes as divisões políticas e sociais tradicionais - centro/periferia, igreja/estado, campo/cidade, proprietários/trabalhadores, partidos políticos, divisões ideológicas do tipo liberalismo/socialismo - podiam definir as grandes linhas do tratamento público dos temas ou acontecimentos cotidianos, hoje em dia, sem que estas divisões tenham desaparecido, predominam, para Dalton, divisões de índole axiológica e temática: valores materiais (habitação, alimentação, saúde, educação), pós-materiais (ecologia, bem-estar, lazer), questões políticas (corrupção), sociais (desemprego), civis (violência de gênero, minorias), econômicas (crise).

Em quarto e último lugar, os novos estilos de cidadania política associam-se à variação do denominado "funil das causalidades": atualmente, a agenda midiática, a imagem dos candidatos, os acontecimentos políticomidiáticos tendem a ter maior peso que os partidos políticos ou as divisões sociais. Essa variação coincide com a erosão das lealdades partidárias ou com 
EID\&A - Revista Eletrônica de Estudos Integrados em Discurso e Argumentação, Ilhéus, n. 16 esp. "Discurso e argumentação na política latino-americana, set.2018.

o predomínio de uma consciência de classe e com a fragmentação dos eleitores que operam em um terreno de maior volatilidade.

A conclusão fundamental de Dalton é que, com esse horizonte, a mobilização partidária (ou até mesmo de classe) compete com a mobilização do tipo cognitivo, nutrida pelo estrondoso papel dos meios de comunicação. Surge, nesse contexto, um novo tipo de cidadão, característico e predominante nas democracias ocidentais contemporâneas, o que Dalton chama de "apartidário" ou "novo independente", marcado por um tipo de mobilização cognitiva apartidária. Ou seja, trata-se de um cidadão muito interessado pela política, mas não a consome de maneira tradicional, filtrada por diferentes lógicas institucionais. Esse novo tipo de cidadão está associado aos tipos "clássicos", configurados nas etapas anteriores das mídias: os independentes apolíticos (sem partido, sem mobilização cognitiva), os partidários rituais (com partido, não cognitivo) e os partidários cognitivos (com partido, cognitivo).

A gradual erosão do campo político, a hipermidiatização e os novos estilos de cidadania política podem ser pensados em relação com o que Brants e Voltmer (2011) denominam os dois desafios à política da 'terceira era da comunicação política'. Fazemos referência aqui à midiatização da política, por um lado, e à descentralização da política, por outro. Em um sentido, existe um desafio para a política do tipo horizontal (interinstituições), que permite ao progressivo predomínio da lógica midiática sobre as pautas da produção da política. A competência pela gestão dos coletivos tem colocado o campo político diante de uma crise de legitimidade. Como assinala Verón (1998), a decadência do campo em que se exercia a gestão dos coletivos em longo prazo (o político) é paralela ao domínio crescente de outro campo (os das mídias) essencialmente orientado pela gestão dos coletivos de curto prazo. Em um sentido diferente, existe um desafio de tipo vertical (dos cidadãos às instituições políticas e midiáticas), que envolve uma posição ativa dos cidadãos, encorajada pela "revolução do acesso". A decepção dos cidadãos com relação aos "representantes" tem, em contrapartida, um ativismo notável, favorecido pelas redes sociais digitais e, muitas vezes, uma concepção não partidária da política. Em síntese, as lógicas do campo político estão, na atualidade, tensionadas pela midiatização da política e pela descentralização das vozes que configuram o público político. 
EID\&A - Revista Eletrônica de Estudos Integrados em Discurso e Argumentação, Ilhéus, n. 16 esp. "Discurso e argumentação na política latino-americana, set.2018.

Gostaria de começar esta última parte deste texto com uma frase de P. Rosanvallon que cito integralmente:

O ideal democrático hoje não tem rival, mas os regimes que o reivindicam suscitam quase em todas as partes fortes críticas. Este é o grande problema político de nosso tempo: "um ódio às democracias". "Historicamente, a democracia [ele acrescenta] manifestou-se sempre como uma promessa e, ao mesmo tempo, um problema. Promessa de um regime de acordo com as necessidades da sociedade; fundada na realização de um duplo imperativo de igualdade e autonomia. Problema de uma realidade que, muitas vezes, está muito distante de ter satisfeito esses nobres ideais. (ROSANVALLON, 2007, p 22).

Para Rosanvallon, esse "grande problema político" tem seu principal fundamento na distância, na "discordância" entre legitimidade e confiança, duas qualidades políticas que a teoria dos governos representativosdemocráticos havia unido no mecanismo eleitoral. No entanto, para o autor, essas duas qualidades não são da mesma natureza: a legitimidade é entendida como uma qualidade jurídica, estritamente procedimental; é produzida de modo perfeito e absoluto pela eleição. A confiança é muito mais complexa. Essa dissociação da legitimidade e da confiança, esse deslocamento ou falta de ajuste, constituiu um problema central na história das democracias. A dissociação tem sido a regra enquanto que a superposição tem sido uma exceção (o que costumamos chamar de 'estado de graça' ou 'primavera presidencial', quando depois de uma eleição, por um período muito breve, as duas qualidades confundem-se excepcionalmente).

A brecha entre legitimidade e confiança nos conduz a uma pergunta que está no cerne da semiótica política contemporânea: como gerar, desdobrar e conservar a confiança nos cidadãos? Essa primeira pergunta supõe uma segunda: como gerenciar ou como regular a configuração das identidades coletivas nas sociedades em que o aspecto público da política circula, como vimos, midiaticamente?

Sabemos que, durante muito tempo, como assinalou Verón (1998), coexistiram duas esferas bem diferenciadas: a esfera política, lugar de construção dos grupos identitários associados à gestão de longo prazo, e a esfera das mídias, lugar de construção de grupos associados, no curto prazo, ao imaginário do cotidiano e aos comportamentos de consumo. A história dos últimos trinta anos nos ensina que esta diferenciação tem perdido, pouco a pouco, sua substância. De todo modo, por um lado, assistimos à decadência 
EID\&A - Revista Eletrônica de Estudos Integrados em Discurso e Argumentação, Ilhéus, n. 16 esp. "Discurso e argumentação na política latino-americana, set.2018.

do campo onde se exercia a gestão dos grupos em longo prazo (o do político) e, por outro, ao domínio crescente de outro campo (o das mídias) essencialmente orientado pela gestão dos grupos de curto prazo. Não seria de toda forma arriscado, se seguíssemos Verón (1998), pensar que o sentido profundo da crise de legitimidade do político - da qual tanto se fala hoje estivesse em boa medida conectado com esta luta.

No entanto, o surgimento e a consolidação (momentânea ou perdurável) dos governos da denominada "virada à esquerda" na América Latina, durante a primeira década do século XXI, exige por entre parênteses a confirmação que Verón realizara tão oportunamente em 1998. (A saber: Hugo Chávez assume a presidência da Venezuela em 2 de fevereiro de 1999). Como foi possível o nascimento de uma série de identidades políticas, de grupos a longo prazo em diferentes países da região, em situações de franca concentração e centralização do sistema de meios de comunicação? Como podemos pensar, compreender, tornar inteligíveis as experiências do $\mathrm{MAS}^{4}$ na Bolívia, da Revolução Cidadã no Equador, do Chavismo na Venezuela, do PT no Brasil, do Kirchnerismo na Argentina, para citar os exemplos mais indiscutíveis? Como foram possíveis, além disso, fazendo em muitos casos as principais corporações de mídia tornarem-se seus adversários diretos mais amargos?

Essas perguntas, feitas a partir de um presente já distante do surgimento de muitas dessas experiências políticas, não podem ser feitas sem considerar como as direitas voltaram a ganhar novamente espaço entre as opções políticas, alcançando posições de governo ou de forte oposição. O caso de Cambiemos, na Argentina é, talvez, o paradigmático, sobretudo se levarmos em conta seu recente e ressonante triunfo eleitoral nas eleições legislativas (em outubro de 2017).

Diante desse cenário, gostaria de terminar abordando uma questão fundamental, estritamente relacionada às duas seções anteriores: a do espetáculo político e suas imagens abundantes, e a das dificuldades das forças políticas para construir fortes identidades entre os cidadãos diante da ruptura de escala insuperável gerada pela midiatização da esfera pública - a midiatização da comunicação política tende a desconstruir a especificidade da comunicação política, conforme E. Verón (1987). Refiro-me às estratégias das

\footnotetext{
${ }^{4}$ NT: O MAS é a denominação alternativa da sigla composta MAS-IPSP - Movimiento al SocialismoInstrumento Político por la Soberanía de los Pueblos. É um partido político boliviano de esquerda socialista fundado em 1987.
} 
EID\&A - Revista Eletrônica de Estudos Integrados em Discurso e Argumentação, Ilhéus, n. 16 esp. "Discurso e argumentação na política latino-americana, set.2018.

formas políticas para "entrar em fase", para comover e convencer a maior quantidade possível de cidadãos, diante do novo cenário político, midiático e cidadão: o cenário dos candidatos-estrelas e os partidos fracos, o cenário dos candidatos fugazes, o cenários das mutações programáticas dos partidos ou de seus líderes, o cenário das redes sociais digitais e a diversificação da oferta de mídia baseada na Internet, o das alianças múltiplas, variáveis e grotescas entre forças de esquerda e de direita, entre corruptos à prova de balas e denunciadores em série, o das velhas práticas de militância política e as novas formas da democracia digital. Em suma: o cenário de uma política desafiada pela midiatização e pela descentralização?

Posso apenas me referir a casos locais, argentinos, que acompanho com interesse nos últimos anos. A Argentina contemporânea tem visto nascer no século XXI duas grandes forças políticas: o kirchnerismo, que tem governado o país desde 2003 até 2015 (a experiência governamental mais longa da historia argentina desde que existe sufrágio universal), e a aliança "Cambiemos", que governa o país desde 2015 até agora (o sucesso eleitoral da força nas recentes eleições de meio termo faz pensar em uma duração que superará os quatro anos.)

Eis aqui uma breve apresentação porque se trata apenas de um esboço, de um trabalho em curso, cujas conclusões estão longe de estar à vista. Em primeiro lugar, gostaria demostrar algumas imagens, imagens da política argentina. São cartazes eleitorais, panfletos de campanha, atos políticos. Correspondem a Cambiemos e al Kirchnerismo (como lhes mencionei, as duas principais forças políticas do presente: a primeira, o governo; a segunda, o exgoverno e principal fluxo de votos de opositor). Concentro-me nelas porque entendo que representam os casos mais emblemáticos, os extremos, de certas formas de imaginar a política, de Ihe dar imagens à política.
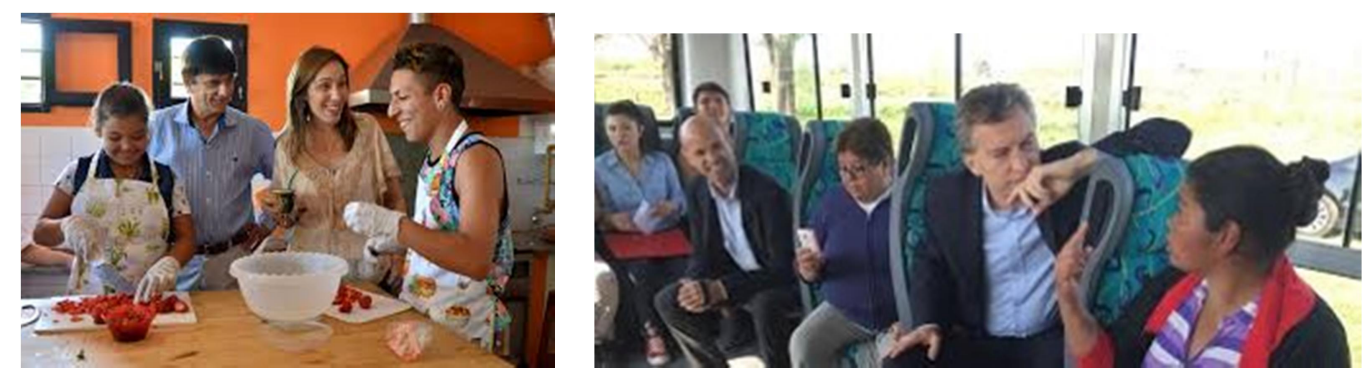


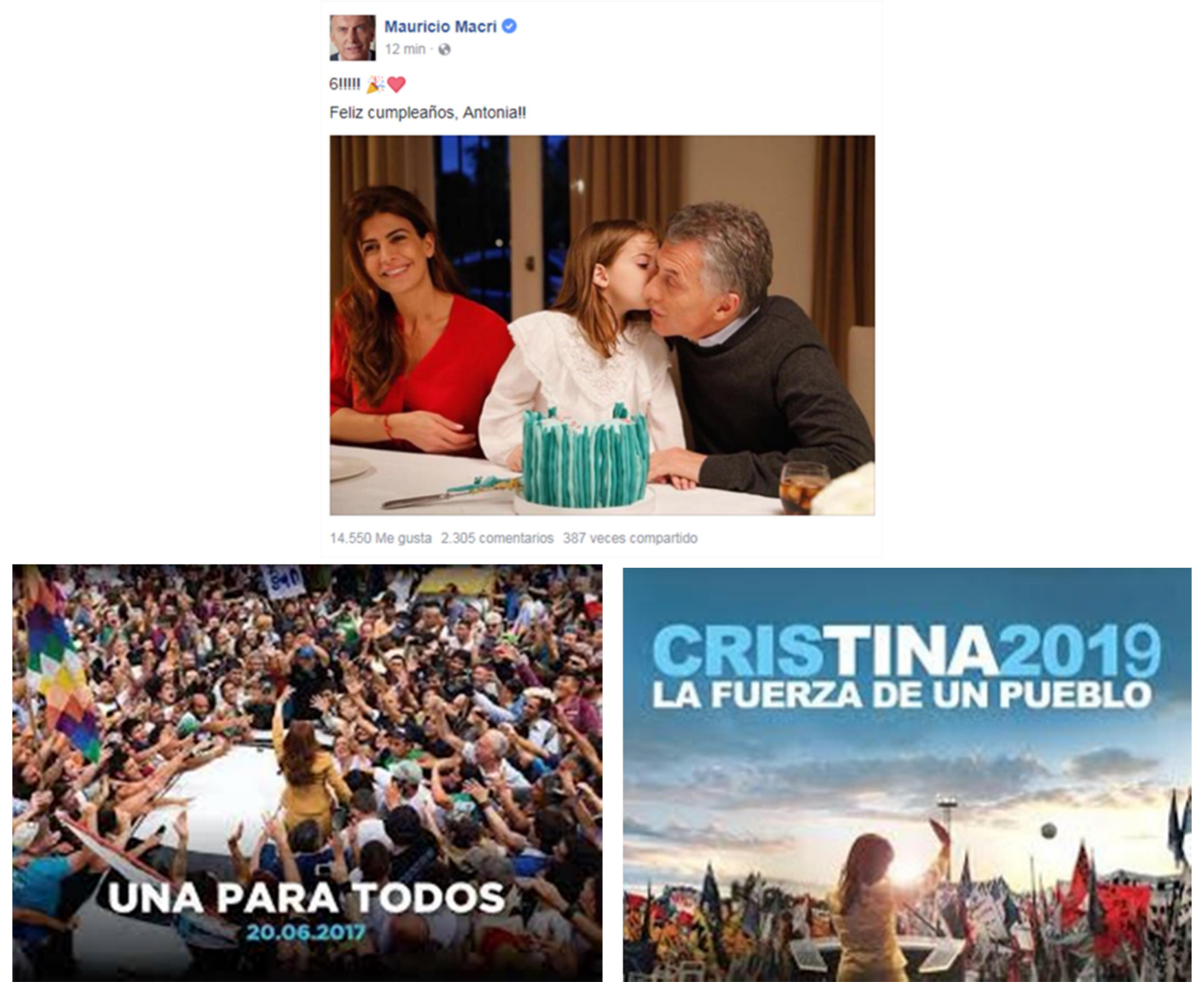

Não teríamos dificuldades para situar estas peças de comunicação política e estes rituais como exemplo do que denominamos na primeira parte da conferência “fotogenia eleitoral”, “teatrocracia”, “videopolítica”. São imagens da política. Em um sentido amplo, generoso, aproximativo. Quero dizer: não se limitam a ser imagens (são gêneros, práticas, rituais), mas têm em comum o fato de serem fenômenos espetaculares. Em sentido literal: entregam-se à visão, à contemplação.

Este é o momento de passar das imagens da política à política das imagens. Considero que não é difícil argumentar que as primeiras permitem inferir as segundas; de todos os aspectos possíveis, vou centrar-me no que poderíamos chamar provisoriamente de a estética das imagens. Defini-la em cada caso me permitirá dar os argumentos finais desta reflexão.

Minha hipótese é a seguinte: na atualidade, na Argentina, convivem grosso modo duas grandes estéticas, cujos máximos expoentes são, como antecipei, o kirchnerismo e Cambiemos. A estética do kirchnerismo, mais convencional, mais clássica, mais tradicional, até o ponto de poder ser 
EID\&A - Revista Eletrônica de Estudos Integrados em Discurso e Argumentação, Ilhéus, n. 16 esp. "Discurso e argumentação na política latino-americana, set.2018.

caracterizada de démodé (assim, de fato, a caracteriza Cambiemos quando fala das "velhas formas"), é de índole romântica, definida por uma exaltação da política como ato vital e autônomo, alimentado pelas convicções, pela coragem, pela vontade. A estética de Cambiemos poderia ser definida, sob o risco de cair em um oximoro, como costumbrismo aspiracional, como veremos mais adiante. No que estas estéticas implicam? Eu posso apenas esboçar algumas características, o que corre o risco de tornar-se uma caricatura.

A estética romântica implica no plano temático uma exaltação da pátria ou da nação, uma exaltação do povo, a benção das lideranças carismáticas; no plano retórico, um romanticismo popular; no plano ritual, a celebração de rituais públicos massivos, que poderiam caracterizar, conforme $M$. Abélès (2016), como rituais de enfrentamento ('enfrentar': trata-se de rituais com um claro conteúdo adversativo). Oferece uma visão coletiva, de multidão, hierárquica da política. Ao contrário da estética costumbrista $a^{5}$, organizada em torno de valores materiais e, sobretudo, pós-materiais (ecologia, lazer, cultura new age, conectividade, velocidade de transporte), os valores que nutrem a estética romântica são eminentemente materiais: habitação, alimentos, saúde, necessidades básicas satisfeitas.

A política é concebida - e sobretudo imaginada - como uma práxis vital e autônoma, intensa, nutrida pelas convicções, pela coragem e pela vontade. Reivindica-se seu papel como produtora e gestora de identidades em longa duração, alimentada pelo peso das tradições e pelas memórias de temas, situações e formas precedentes (CHARAUDEAU, 2006). Os temas trabalhados, os mundos compartilhados, as filiações sugeridas, os dispositivos utilizados, os contratos de comunicação estabelecidos, as maneiras de dizer e os estilos de fala e de presença corporal apostam em gerar comunidades discursivas, comunicacionais e semiológicas duradouras (as batidas do futuro são os ecos do passado).

A estética romântica está organizada em torno de relações que, conforme G. Bateson (1998), poderíamos chamar de "complementaridade": lideranças fortes, matrizes pedagógicas de transmissão de valores transcendentais (a militância juvenil assegura a transmissão entre gerações). Não coincidentemente, o campo do conhecimento e o campo do dever ocupam espaços importantes da retórica: percebe-se uma ostentação do

\footnotetext{
${ }^{5}$ NT: O termo refere-se a uma tradição dentro das correntes artísticas visuais e literárias, compreendendo os usos e costumes da sociedade. O movimento surgiu na Espanha associado ao mito romântico e expandiu-se na Hispano-América no século XIX.
} 
EID\&A - Revista Eletrônica de Estudos Integrados em Discurso e Argumentação, Ilhéus, n. 16 esp. "Discurso e argumentação na política latino-americana, set.2018.

saber que supõe um vínculo privilegiado com a verdade. Privilegiam-se gêneros monológicos da encenação da política: desde discursos de púlpito em cerimônias mais ou menos institucionais, mais ou menos populares, até cartazes e panfletos. Muitas vezes, a encenação pode sugerir gêneros pedagógicos: aulas, conferências, doutrinação militante. São discursos invariavelmente midiatizados que procuram, no entanto, não subordinar-se às lógicas institucionais dos meios de comunicação: sua estética lembra com frequência a de uma política pré-televisiva. Alimenta seu imaginário de situações de enunciação que parecem tangenciais a situações de comunicação da política televisionada: desde rituais de multidões até aulas, nenhum destes nasceu para a televisão (nenhum é fruto direto da presença central da televisão), ainda que possam ser obviamente televisionados.

A estética romântica organiza uma ética da hiperpolitização que confere ao político uma práxis excepcional, autônoma, cujos contornos em relação à vida cotidiana, aos hábitos e aos costumes aparecem, muitas vezes, esculpidos com pulso firme. Imagina-se uma cidadania de alta intensidade. Subordina, relega (ou inclusive pode até tabular) a representação política dos espaços privados, considerados externos ou alheios às dinâmicas políticas. Sua imaginação política é, principalmente, épica, não doméstica; criativa, performativa, não reprodutiva; coletiva, não individual.

A estética do costumbrismo aspiracional aposta em uma imaginação política da vida cotidiana. Seus espaços representados são casas (de preferência humildes), praças (espaço de bairros por excelência), locais de trabalho sem multidões (campos, pequenos comércios). Práticas como ir batendo de porta em porta ${ }^{6}$, fazer pequenas caminhadas, manter conversas telefônicas, por exemplo, estabelecem uma relação próxima entre os atores políticos e os cidadãos comuns.

O costumbrismo aspiracional implica uma exaltação de valores que podem coincidir com os da épica romântica: o trabalho, o esforço, a construção eufórica dos setores populares; porém, esses valores têm uma dimensão mais privada do que pública, mais individual do que coletiva: trata-se de cada trabalhador, de cada família, de cada vizinho, afastada de qualquer memória comunitária (a exceção, talvez, da nacional). O líder é carente de carisma, mas Ihe sobra proximidade. Seus valores são a escuta, a falibilidade, a

\footnotetext{
${ }^{6}$ NT: O autor usa a expressão "el timbreo" no sentido de "tocar timbre" (tocar campainha) como uma prática adotada por Cambiemos, que, em uma ação política, visita os vizinhos, toca a campainha de uma casa e bate um papo.
} 
EID\&A - Revista Eletrônica de Estudos Integrados em Discurso e Argumentação, Ilhéus, n. 16 esp. "Discurso e argumentação na política latino-americana, set.2018.

proximidade, a humildade (não importa que se trate de um milionário, porque pode ser milionário e humilde ao mesmo tempo). Os rituais políticos mais clássicos - os atos políticos, por exemplo - parecem ser executados (quando são executados, porque são realmente escassos) como rituais de consenso, que exaltam os valores compartilhados de todos os argentinos. Oferece-se uma visão agregadora, individual e simétrica da política.

A política se dissolve no cotidiano, como se, em contraste com a intensidade hipostasiada da estética romântica, a baixa intensidade fosse a maneira natural de experimentar a política. Quero dizer que, ao contrário de uma visão intensa/autônoma da experiência política, assistir televisão, trabalhar, comer com a família, tomar uma chá mate, levar o cachorro para passear, brincar com os filhos é o papel político de cada cidadão. (Nesse sentido, diferentemente da estética romântica, a costumbrista aproveita a seu favor a ampliação do dizer político). A política não é feita fora da vida, não é experimentada fora da vida; é feita sem fazer, vivendo, pela força do hábito e dos objetivos diários, que nunca pode ultrapassar o horizonte do bairro, do quarteirão, da esquina, da casa (a menos que se trate, naturalmente, da nação como uma linha de fuga).

Sabemos que o natural é um álibi das regras, mas a estética costumbrista aspiracional joga para transformar as grandes melodias da política no toque de um celular. A propósito de Cambiemos, o filósofo argentino G. Varela (2016) disse: "O governo Pro não foi votado, foi rebaixado por $51 \%$ dos usuários". Qualquer um que tenha lido La política del siglo XXI, de Duran Barba e Nieto (2018), os responsáveis pela comunicação política do atual governo argentino, pode observar com relativa facilidade que, de acordo com os autores, a política não tem outro propósito senão o de devolver como uma oferta à sociedade o que a sociedade exige. Uma espécie de espelho construído com complexas e caras técnicas de medição quantitativa e qualitativa. Esse "deslocamento zero" entre oferta e demanda, que nada mais é do que uma ficção ad hoc dos assessores , esquece, evidentemente, que as leituras que um governo ou uma força política faz das demandas sociais é profundamente performativa; isto é, tende a construir, retrospectivamente, as demandas a que se comprometeu satisfazer.

Por que este costumbrismo, que até aqui descrevemos, seria aspiracional? Minha resposta, provisória, é a seguinte: porque em sua estética misturam-se os costumes das classes baixas e meio baixas com os costumes 
EID\&A - Revista Eletrônica de Estudos Integrados em Discurso e Argumentação, Ilhéus, n. 16 esp. "Discurso e argumentação na política latino-americana, set.2018.

das classes alta e meio alta. Sabemos que cada setor social tem seus costumes, e a estética aspiracional tende a conectá-los sem solução de continuidade: os cartazes e os panfletos de campanha de Cambiemos com os candidatos, conversando em uma casa ou em uma praça e tomando mate ou comendo bolinhos fritos, coexistem com cerimonias rituais que só podem ser associadas, por suas formas e seus gostos, com as das classes mais abastadas - uma combinação de festa de empresas com celebridades familiares high class. Um exemplo notório e repetido são os festejos no bunker de Cambiemos depois que se soube dos resultados eleitorais: escutamos a cumbia de Gilda com o rock careta de Tan Biónica e com o hip hop chileno de Croni-K. Em seu livro Mundo Pro, G. Vommaro, S. Morresi y A. Bellotti (2015) descrevem com precisão, a partir de um trabalho de observação participativa, como as diferentes cerimônias de PRO estão organizadas com um formato que lembra as festas das grandes empresas nacionais e internacionais, com seu cerimonial, seu catering e suas confraternizações.

Se as memórias da estética romântica inscrevem-se nas tradicionais manifestações de massas, em motivos, temas e cenas clássicas do romantismo literário ou pictórico (desde o Fausto, de Goethe, até a Liberdade guiando o povo, de Eugène Delacroix) e nas práticas que remetem a formas clássicas de fazer política - a oratória prolongada, a tarefa da militância etc. -, as memórias da estética costumbrista aspiracional fazem, por um lado, em motivos, temas e cenas do costumbrismo (que, não esqueçamos, é uma derivação do romanticismo popular) e, por outro, de uma maneira geral na Argentina, em formatos, cenas e práticas que só podem se associar a diferentes vetores do cotidiano das classes mais endinheiradas do país.

O costumbrismo aspiracional, paradoxalmente, está organizado em torno das relações de simetria nas quais a distribuição cima/baixo, rico/pobre dá lugar a uma gradualidade de nuances. A concepção discreta, segmentada das posições dos diferentes setores sociais se apaga em benefício de uma concepção contínua, gradual, invariavelmente individual do lugar de cada cidadão no mundo, deixando entrever a possibilidade de mobilidade social (fortemente ancorado no imaginário argentino) como um horizonte concreto, cuja realização depende das trajetórias individuais. As conferências de imprensa, a descentralização das vozes autorizadas (não mais o líder carismático, mas um conjunto de vozes escalonadas ainda que dispersas), as entrevistas deixariam ver, com distância da estética romântica, uma ênfase em 
EID\&A - Revista Eletrônica de Estudos Integrados em Discurso e Argumentação, Ilhéus, n. 16 esp. "Discurso e argumentação na política latino-americana, set.2018.

gêneros dialógicos da encenação que, de modo algum, obturam a existência de gêneros monológicos por mais que se espere.

Finalmente, a estética do costumbrismo aspiracional organiza uma ética da hipopolitização, retornando para o político uma práxis indecifrável do cotidiano, natural, com pleno emprego de ênfase, cujos contornos a propósito dos hábitos e dos costumes individuais ou familiares desaparecem. Imagina-se uma cidadania de baixa intensidade. A representação política dos espaços privados é um núcleo duro deste costumbrismo, que, no entanto, não relega a representação política dos espaços públicos, embora pareça "formatar" com traços genéricos do que chamaríamos de "eventos privados". O uso do imaginário das redes sociais digitais é, nesse sentido, decisivo: o costumbrismo aspiracional integra uma memória discursiva comunicacional e semiótica que imita o uso das redes que qualquer pessoa pode fazer: difusão de questões públicas e privadas, cenas familiares, práticas como ir de porta em porta, felicidade em toda parte, uma retórica do espontâneo etc. (Também se brinca com a imaginação de uma comunidade moderna nessas áreas).

\section{Breves considerações finais}

Essas estéticas, a romântica e a costumbrista aspiracional, não esgotam as estéticas políticas da Argentina contemporânea. Contudo, acredito que seu estudo, isto é, o estudo das políticas das imagens das principais forças políticas esclarece os modos de funcionamento de uma hegemonia discursiva. Estudar a multiplicidade de discursos que dão imagens à política contemporânea tem como principal objetivo, a meu ver, indagar a gramática, o sistema regulador global que lhes dão força. Tentar estabelecer princípios explicativos de uma quantidade inumerável de fenômenos ligados às identidades e à comunicação política não tem outra finalidade senão dar passos firmes na compreensão da atual situação política. Considero que nossa tarefa como semiólogos ou analistas do discurso é apostar em desfazer os complexos dispositivos de palavras, imagens e sons a partir dos quais - como afirmava Courtine (2006) - se exercem formas inéditas de dominação política que são, justamente, as que hoje nos colocam em armadilhas. 
EID\&A - Revista Eletrônica de Estudos Integrados em Discurso e Argumentação, Ilhéus, n. 16 esp. "Discurso e argumentação na política latino-americana, set.2018.

\section{Referências}

ABÉLÈS, Marc. El espectáculo del poder. Buenos Aires: Prometeo, 2016.

ADVERSE, Helton. Maquiavel: política e retórica. Belo Horizonte: Ed.UFMG, 2009.

AMOSSY, Ruth. Apologie de la polemique. Paris: PUF, 2014.

BALANDIER, Georges. El poder en escena: de la representación del poder al poder de la representación. Barcelona: Paidós, 1994.

BARTHES, Roland. Retórica de la imagen. In: Lo obvio y lo obtuso. Barcelona: Paidós, 1982. p. 29-47.

BARTHES, Roland. Mitologías. Buenos Aires: Siglo veintiuno editores, 2004.

BATESON, Gregory. Pasos hacia una ecología de la mente. Buenos Aires: Lumen, 1998.

BERGER, John. Modos de ver. Barcelona: Gustavo Gilli, 2000.

BRANTS, Kornelis; VOLTMER, Katrin. Political Communication in Postmodern Democracy: Challenging the Primacy of Politics. Basingstoke: Palgrave Macmillan, 2011.

CARLÓN, Mario. Público, privado e íntimo: el caso Chicas bondi y el conflicto entre derecho a la imagen y libertad de expresión en la circulación contemporánea. In: CASTRO, Paulo Cesar (Org.). Dicotomía público/privado: estamos no camino certo? Maceió: EDUFAL, 2015.

CARLÓN, Mario; SCOLARI, Carlos. El fin de los medios masivos: el comienzo de un debate. Buenos Aires: La Crujía, 2009.

CENTOCCHI, Claudio; TATAVITTO, María; VARELA, Graciela. Espacios, escenarios y cuerpos: dos momentos del programa político de opinión. In: Del COTO, M. (Comp.). La discursividad audiovidual. Aproximaciones semióticas. Buenos Aires: Docencia, 2003.

CHARAUDEAU, Patrik. Discurso político. São Paulo: Contexto, 2006.

COURTINE, Jean-Jacques. Metamorfoses do discurso político: derivas da fala pública. São Carlos: Claraluz, 2006.

; PIOVEZANI, Carlos (Org.). História da fala pública. Uma arqueologia dos poderes do discurso. São Paulo: Ed.Vozes, 2015.

CULLER, Jonathan. Barthes: a very short introduction. Nueva York: Oxford University Press, 2002. 
EID\&A - Revista Eletrônica de Estudos Integrados em Discurso e Argumentação, Ilhéus, n. 16 esp. "Discurso e argumentação na política latino-americana, set.2018.

DALTON, Russell. Citizen Politics: Public Opinion and Political Parties in Advanced Industrial Democracies. Los Angeles: Sage Publications, 2014.

DE ÍPOLA, Emilio. Ideología y discurso populista. México: Folios, 1982.

DURÁN BARBA, Jaime; NIETO, Santiago. La política en el siglo XXI: Arte, mito o ciencia. Buenos Aires: Debate, 2018.

FOUCAULT, Michel. Vigilar y castigar: nacimiento de la prisión. Buenos Aires: Siglo Veintiuno editores, 2002.

JAY, Martin. Ojos abatidos: la denigración de la visión en el pensamiento francés del siglo XX. Madrid: Akal, 2007.

LE BART, Christian. Le discours politique. Paris: PUF, 1998.

- L'analyse du discours politique: de la théorie des champs à la sociologie de la grandeur. Mots, n. 72, p. 97-110, 2003.

LIPOVETSKY, Gilles. La era del vacío: ensayos sobre el individualismo contemporáneo. Barcelona: Anagrama, 2015.

; SERROY, Jean. La estetización del mundo. Vivir en la época del capitalismo artístico. Barcelona: Anagrama, 2015.

LUHMANN, Niklas. Confianza. Barcelona: Anthropos, 2005.

MORIN, Edgard. El cine o el hombre imaginario. Barcelona: Paidós, 2011.

RANCIÈRE, Jacques. El espectador emancipado. Buenos Aires: Manantial, 2010.

ROSANVALLON, Pierre. La contrademocracia: la política en la era de la desconfianza. Buenos Aires: Manantial, 2007.

. La legitimidad democrática: imparcialidad, reflexividad, proximidad. Buenos Aires: Manantial, 2009.

SARLO, Beatriz. Siete hipótesis sobre videopolítica. In: . Instantáneas. Medios, ciudad y costumbres en el fin de siglo. Buenos Aires: Ariel, 1996. p. 149-160.

SARTORI, Giovanni. Homo videns: la sociedad teledirigida. México: Taurus, 1998.

TILLY, Charles; WOOD, Lesley. Los movimientos sociales, 1768-2008. Desde sus orígenes a Facebook. Barcelona: Crítica, 2014.

VARELA, Gustavo. Son horribles. Blog El furgón, Buenos Aires, 2016. Disponível em: http://elfurgon.com.ar/2016/10/26/son-horribles/

VERÓN, Eliseo. La palabra adversativa. Observaciones sobre la enunciación política. In: AA.VV. El discurso político. Buenos Aires: Hachette, 1987. p. 11-26. 
EID\&A - Revista Eletrônica de Estudos Integrados em Discurso e Argumentação, Ilhéus, n. 16 esp. "Discurso e argumentação na política latino-americana, set.2018.

- Mediatización de lo político. Estrategias, actores y construcción de colectivos. In: GAUTHIER, Gilles; MOUCHON, Jean (Comp.). Comunicación y política. Barcelona, Gedisa, 1998.

. La semiosis social, 2. Ideas, momentos, interpretantes. Buenos Aires: Paidós, 2013.

VOMMARO, Gabriel; MORRESI, Sergio; BELLOTI, Alejandro. Mundo Pro. Anatomía de un partido fabricado para ganar. Buenos Aires: Planeta, 2015.

Tradução:

Thiago Augusto Carlos Pereira

Graduando em Letras pela Universidade Federal da Integração Latino-Americana (UNILA)

Jocenilson Ribeiro

Docente da Universidade Federal da Integração Latino-Americana (UNILA)

Forma de citação sugerida:

DAGATTI, Mariano. Imagens da política, política das imagens: sobre comunicação, retórica e estética. Trad. Thiago Augusto Carlos Pereira e Jocenilson Ribeiro. EID\&A Revista Eletrônica de Estudos Integrados em Discurso e Argumentação, Ilhéus, n. 16 esp. “Discurso e argumentação na política latino-americana”, p. 274-298, set.2018.

Recebido em: 25/07/2018

Aprovado em: 26/08/2018 